\title{
Determining the Safety and Effectiveness of Electrocautery Enhanced Scissors for Peroral Endoscopic Myotomy (with Video)
}

\author{
Kelly E. Hathorn, Walter W. Chan, Hiroyuki Aihara and Christopher C. Thompson \\ Division of Gastroenterology, Hepatology and Endoscopy, Brigham and Women's Hospital, Harvard Medical School, Boston, MA, USA
}

Background/Aims: Peroral endoscopic myotomy (POEM) has recently come to the forefront in the management of achalasia. We aimed to analyze the efficacy and safety of the use of electrocautery enhanced scissors (EES) for POEM.

Methods: This retrospective cohort study prospectively collected the data of all adult patients (aged $\geq 18$ years) with normal foregut anatomy who underwent POEM using EES. The patients' baseline characteristics and procedure details (time, tunnel length, myotomy length, depth, and location) were recorded. The primary outcome was clinical success (3-month post-procedure Eckardt score of $\leq 3$ ). The secondary outcomes were technical success and adverse events. A paired Student's $t$-test was performed.

Results: Fifteen patients were included in this study. The technical success rate of myotomy using EES was $100 \%$. Fellows participated in the myotomy in all cases. The clinical success rate was $93.3 \%(14 / 15)$. The mean pre-Eckardt score was $5.4 \pm 2.5$, while the mean post-Eckardt score was $1.3 \pm 1.3$, which indicated a significant improvement $(p \leq 0.0001)$. The most common treatment-related adverse events were post-procedure pain $(4,26.7 \%)$ and symptomatic reflux disease $(4,26.7 \%)$.

Conclusions: In the largest series to date on the use of EES in POEM, we demonstrated that this technique has both technical and clinical efficacy as well as an excellent safety profile. Clin Endosc 2020;53:443-451

Key Words: Achalasia; Electrocautery enhanced scissors; Hybrid knife; Peroral endoscopic myotomy

\section{INTRODUCTION}

Achalasia, a disorder of esophageal dysmotility, is characterized by failure of the lower esophageal sphincter (LES) to relax and the lack of functional peristalsis in the esophageal body because of progressive degeneration of ganglion cells in the myenteric plexus of the esophageal wall. Clinically, patients develop dysphagia, regurgitation, heartburn, chest pain, and/ or weight loss. Although the severity of symptoms may vary, the disease burden is high, and achalasia can have a significant impact on patient's health-related quality of life.

Received: November 13, 2019 Revised: February 4, 2020

Accepted: February 25, 2020

Correspondence: Christopher C. Thompson

Division of Gastroenterology, Hepatology and Endoscopy, Brigham and Women's Hospital, Harvard Medical School, 75 Francis St., Boston, MA 02115, USA Tel: +1-617-732-5500, Fax: +1-617-264-6342, E-mail: cthompson@hms.harvard.edu ORCID: https://orcid.org/0000-0002-6105-5270

(c) This is an Open Access article distributed under the terms of the Creative Commons Attribution Non-Commercial License (http://creativecommons.org/ licenses/by-nc/3.0) which permits unrestricted non-commercial use, distribution, and reproduction in any medium, provided the original work is properly cited.
Peroral endoscopic myotomy (POEM) is an endoscopic procedure, which combines the minimally invasive benefit of endoscopy with the durability of a surgical myotomy. POEM involves endoscopic submucosal tunneling, followed by dissection and division of the circular muscle fibers of the esophagus and LES. Although the steps of the procedure are generally performed similarly in institutions across the world, there is some variability with regard to the equipment used to perform POEM. ${ }^{1,2}$ Previous studies have investigated the use of conventional versus hybrid knife in $\mathrm{POEM}^{1}$; however, little is known about the safety and efficacy of electrocautery enhanced scissors (EES) in esophageal myotomy. Although the use of an additional device may increase procedure time and cost, the benefits of using this device, including improved accuracy and precision of myotomy, ability to provide hemostasis without the need to exchange devices, and improved safety in training fellows, make this a viable tool for POEM. Thus, this study aimed to analyze the safety and efficacy of the use of EES in POEM at an academic institution with a fellowship training program. 


\section{MATERIALS AND METHODS}

In this retrospective cohort study, the data of adult patients aged $\geq 18$ years with normal foregut anatomy who underwent POEM using EES between September 2017 and November 2018 at a large academic institution in Boston, MA, USA were prospectively collected. This study was approved by the Institutional Review Board. During this prospective series, all myotomy procedures were performed by our group using EES. Patients' baseline characteristics, including indications for intervention, and procedure details (procedure time, tunnel length, myotomy length and depth, and myotomy location) were recorded.

\section{Peroral endoscopic myotomy procedure}

POEM procedures were performed in a manner similar to that initially described by Inoue et al., ${ }^{3}$ and further details on the endoscopic myotomy using the EES device are described below. A forward-viewing upper endoscope (GIFHQ190; Olympus America, Center Valley, PA, USA) and an electrosurgical generator (VIO 300 D; Erbe USA, Marietta, GA, USA) were used for all POEM procedures. A tapered-tip distal attachment cap (ST Hood; Fujifilm Medical Systems, Stamford, CT, USA) and DualKnife J (Olympus) or FlushKnife (Fujifilm) were used for submucosal tunneling (Endocut [Effect 2, Cut Duration 2, Cut Interval 2], Spray Coag effect 2, $50 \mathrm{~W}$ ), and a regular attachment cap (Olympus) and EES (SB Knife Jr; Olympus; Fig. 1) were used for the myotomy (Endocut [Effect 2, Cut Duration 2, Cut Interval 2], Soft Coag effect 5, $50 \mathrm{~W}$ ). The EES device can be used through a standard upper diagnostic endoscopic channel and is operated by both the endoscopist and an assistant. EES is a fully rotatable knife that can be maneuvered independently by the physician, which allows cutting in a horizontal or vertical axis. ${ }^{4}$ It has an insulat-

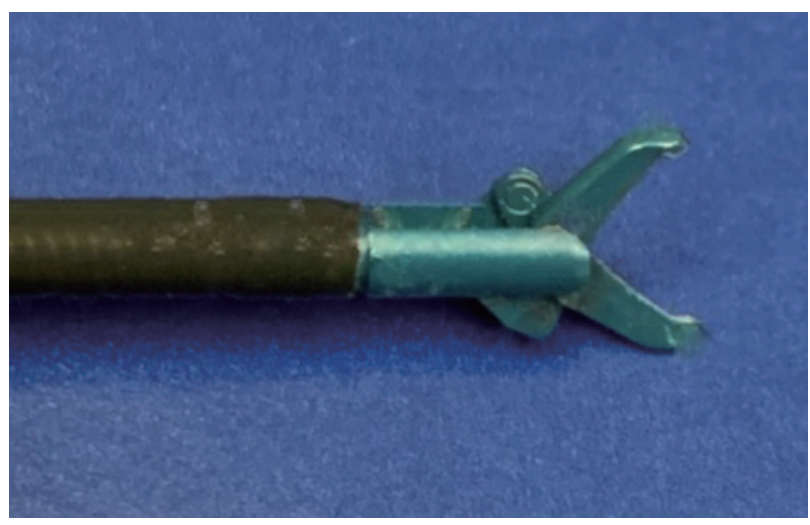

Fig. 1. Electrocautery enhanced scissors. (SB Knife Jr; Olympus America, Center Valley, PA, USA). ed scissor-type blade that is lined with a cutting electrode and allows the endoscopist to pull the tissue backward toward the scope prior to cutting to minimize the risk of tissue damage or perforation. ${ }^{4}$ Hemostatic forceps (Coagrasper; Olympus) was used for sealing of larger vessels and hemostasis (Soft Coag effect 5, $50 \mathrm{~W}$ ). A carbon dioxide insufflator was used in all cases. For final closure of the mucosal entry site, hemostatic clips (DuraClip; CONMED, Utica, NY, USA) or endoscopic suturing device (OverStitch ${ }^{\mathrm{TM}}$; Apollo Endosurgery, Austin, TX, USA) was used. Patients fasted for $>12$ hours prior to the POEM, which was performed under general anesthesia with endotracheal intubation. All procedures were supervised or performed by a senior endoscopist (HA or CCT) with either a general gastroenterology or an advanced endoscopy fellow. All patients were admitted to the inpatient ward following the procedure for observation. Patients were kept nil per os and received intravenous (IV) proton-pump-inhibitor (PPI) and IV ciprofloxacin and metronidazole overnight. On post-operative day 1 , patients underwent a barium swallow to assess for perforation or leak. Patients' diet was then advanced to a clear liquid diet for 2 days, followed by a full liquid diet for 12 days, and then a soft diet with advancement as tolerated. Patients continued oral PPI for 8 weeks and completed a total of a 5 -day course of ciprofloxacin and metronidazole.

\section{Endoscopic myotomy}

First, the internal circular muscle bundle at approximately $2 \mathrm{~cm}$ distal to the mucosal entry was cut using EES (Endocut [Effect 2, Cut Duration 2, Cut Interval 2]) until the external longitudinal muscle bundle was exposed (Fig. 2). Then, selective internal circular myotomy was performed. Possible blood

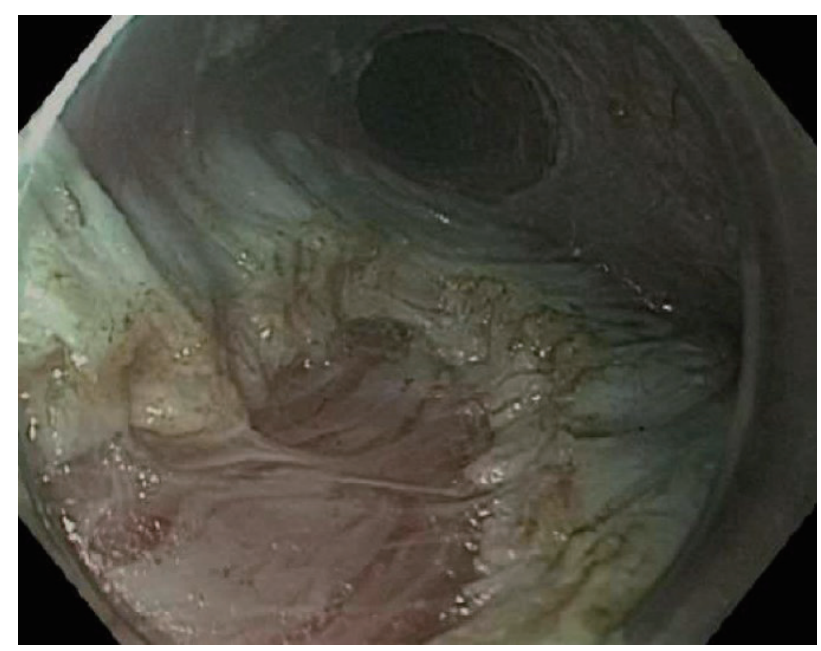

Fig. 2. Initial site of myotomy, approximately $2 \mathrm{~cm}$ distal to the mucosal entry site. 

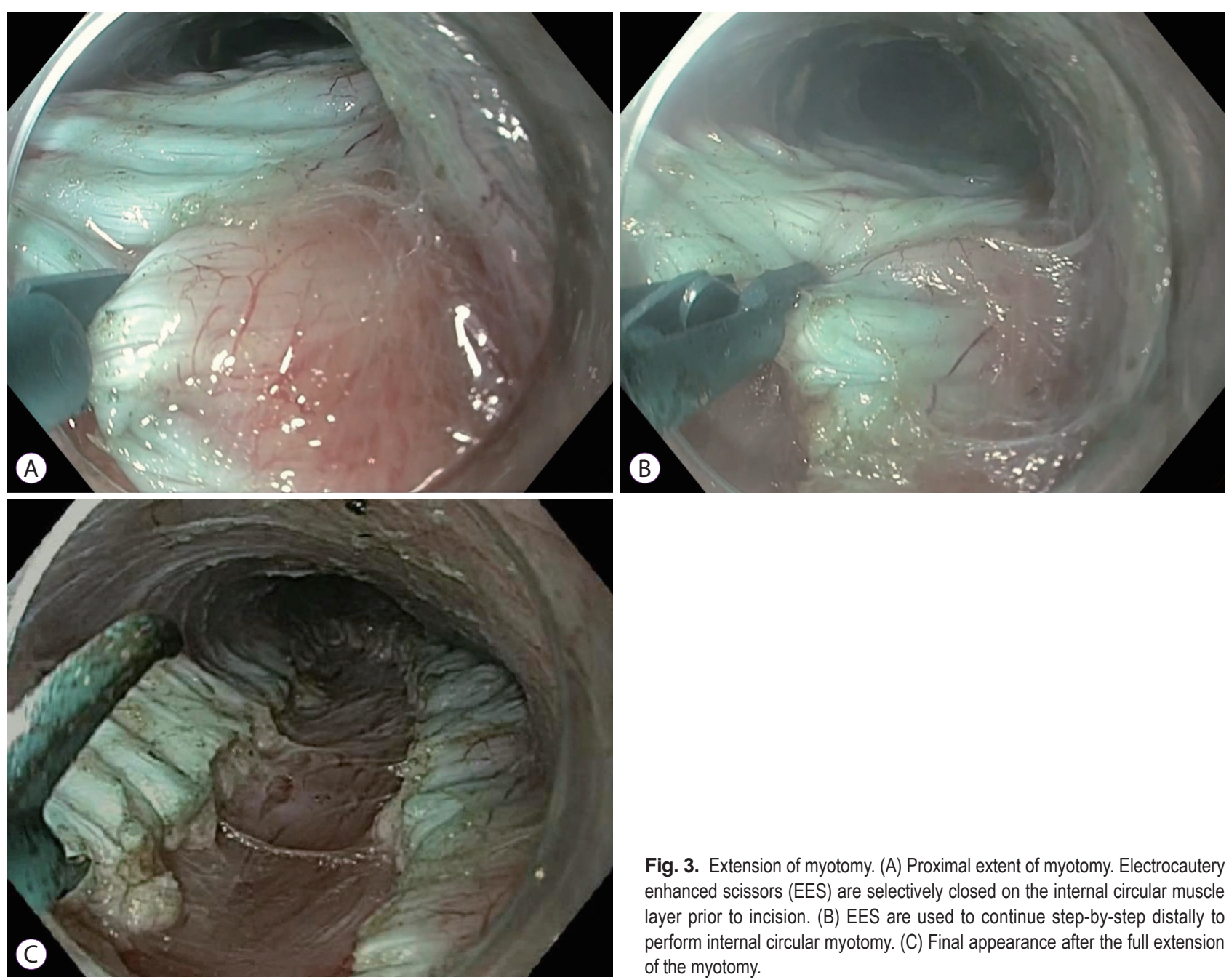

Fig. 3. Extension of myotomy. (A) Proximal extent of myotomy. Electrocautery enhanced scissors (EES) are selectively closed on the internal circular muscle layer prior to incision. (B) EES are used to continue step-by-step distally to perform internal circular myotomy. (C) Final appearance after the full extension of the myotomy.

vessels were preemptively cauterized using the EES with Soft Coag mode (effect 5, $50 \mathrm{~W}$ ) before cutting the muscle fibers. The myotomy was then continued step by step distally until it extended approximately $2 \mathrm{~cm}$ distal to the gastroesophageal junction (GEJ) (Fig. 3). After completion of the myotomy, the endoscope was reinserted into the esophagus to confirm smooth passage through the GEJ (Supplementary video 1).

\section{Outcome parameters, efficacy, and safety}

All patients were scheduled for follow-up visits at 1, 3, and 6 months after the POEM procedure. The primary outcome of this study was clinical success, defined as a 3-month post-procedure Eckardt score of $\leq 3$. The secondary outcomes were technical success, defined as successful completion of the myotomy, and treatment-related adverse events, separated into mild, moderate, or severe events, adapted from previous American Society of Gastrointestinal Endoscopy (ASGE) recommendations. ${ }^{5}$ Mild complications were defined as those that required post-procedure medical consultation or unplanned prolongation of hospital stay for $\leq 3$ nights. Moderate complications were defined as those that need additional monitoring but required a hospital stay of only 4-10 nights and/or an intensive care unit (ICU) admission of 1 night. Severe complications were defined as those that were potentially life-threatening, requiring a hospital stay of $>10$ nights and/ or ICU monitoring of $>1$ night, and/or requiring surgical or re-intervention for adverse events.

\section{Statistical analysis}

Parametric data were presented as mean \pm standard deviation, while non-parametric data were presented as median (range). Statistical differences were analyzed using paired Student's $t$-test. A $p$-value of $<0.05$ was considered significant. 


\section{RESULTS}

\section{Patient baseline characteristics}

Fifteen patients with normal foregut anatomy underwent POEM with EES knife for myotomy and were included in our analysis. The patients' characteristics are listed in Table 1. The patients' mean age was $51 \pm 19.4$ years (range, $29-84$ years), mean body mass index was $28 \pm 8.9 \mathrm{~kg} / \mathrm{m}^{2}$, and mean Charlson Comorbidity Index was $2.1 \pm 2.9$ (range, $0-8$ ). Six of the fifteen patients (40\%) had type 1 achalasia, six (40\%) had type 2 achalasia, one (6.7\%) had type 3 achalasia, one had an achalasia diagnosis not otherwise specified (6.7\%), and one had esophagogastric junction outflow obstruction (6.7\%). Twelve of the fifteen patients (80\%) received alternative therapy prior to POEM, including balloon dilation (5/15 patients, 33.3\%), pneumatic dilation (4/15 patients, 26.7\%), and/or botulinum toxin injection (6/15 patients, $40 \%)$. None of the patients had history of Heller myotomy or POEM procedure.

\section{Procedure details}

Fourteen of the fifteen (93.3\%) myotomy procedures were performed in the posterior location, and all were selective partial-thickness myotomy procedures. Fourteen of the fifteen (93.3\%) myotomies were closed with endoscopic clips (range, 4-9 clips), and one of the fifteen (6.7\%) was closed with endoscopic suturing. Given that many other centers use an endoscopic suturing device for closure, we tested this in one of our earlier cases; however, it was our preference to perform all other cases with endoscopic clips. The mean length of myotomy was $11.6 \pm 3.7 \mathrm{~cm}$, with a mean tunnel length of $13.2 \pm 3.3 \mathrm{~cm}$. The mean length of procedure was $84 \pm 29$ minutes.

\section{Primary outcome}

POEM was clinically successful in fourteen of the fifteen patients $(93.3 \%)$ at 3-month follow-up. The mean pre-Eckardt score was $5.4 \pm 2.5$, and the mean post-Eckardt score was $1.3 \pm 1.3$, with a mean improvement of $4.1 \pm 2.7$ ( $p \leq 0.0001$; Fig. 4). On Eckardt sub-score analysis, there was a statistically significant improvement in dysphagia (pre-POEM: $2.4 \pm 1.1$ vs. post-POEM: $0.5 \pm 0.8$, mean improvement $1.8 \pm 1.2$, $p=0.0001$; Fig. 5) and regurgitation (pre-POEM: $1.7 \pm 1.2$ vs. post-POEM: $0.3 \pm 0.6$, mean improvement $1.2 \pm 1.5, p=0.0136$; Fig. 6), but not chest pain (pre-POEM: $0.6 \pm 0.9$ vs. post-POEM: $0.2 \pm 0.4$, mean improvement $0.4 \pm 1.0, p=0.2087$; Fig. 7 ) or weight loss (pre-POEM: $0.5 \pm 1.0$ vs. post-POEM: $0.1 \pm 0.3$, mean improvement $0.4 \pm 1.0, p=0.2087$; Fig. 8 ).

\section{Secondary outcomes}

Myotomy was technically successful in all fifteen patients (100\%). All patients were admitted to the hospital for observation following the procedure. The mean length of hospital stay post-procedure was $1.8 \pm 2.4$ days. Seven of the fifteen patients $(46.7 \%)$ did not experience any treatment-related adverse events. Six patients (40\%) experienced a mild adverse

Table 1. Baseline Patient Characteristics

\begin{tabular}{|c|c|c|c|c|c|c|}
\hline & Age (yr) & Sex & BMI $\left(\mathrm{kg} / \mathrm{m}^{2}\right)$ & CCI & Diagnosis & Prior therapy \\
\hline Patient 1 & 37 & $\mathrm{~F}$ & 23.1 & 0 & Type 1 achalasia & Balloon dilation \\
\hline Patient 2 & 68 & M & 25.9 & 3 & Type 3 achalasia & Balloon dilation \\
\hline Patient 3 & 34 & M & 28.8 & 0 & Achalasia NOS & Botulinum injection \\
\hline Patient 4 & 48 & $\mathrm{~F}$ & 35.9 & 0 & Type 2 achalasia & Balloon dilation, botulinum injection \\
\hline Patient 5 & 31 & $\mathrm{~F}$ & 23.9 & 0 & Type 2 achalasia & Botulinum injection \\
\hline Patient 6 & 84 & $\mathrm{~F}$ & 21.9 & 8 & Type 1 achalasia & Botulinum injection \\
\hline Patient 7 & 55 & $\mathrm{~F}$ & 23.1 & 1 & Type 1 achalasia & Botulinum injection \\
\hline Patient 8 & 76 & $\mathrm{~F}$ & 31.8 & 8 & Type 2 achalasia & N/A \\
\hline Patient 9 & 52 & $\mathrm{~F}$ & 18.1 & 1 & Type 1 achalasia & N/A \\
\hline Patient 10 & 72 & $\mathrm{~F}$ & 20.4 & 5 & Type 2 achalasia & Pneumatic dilation \\
\hline Patient 11 & 22 & M & 25.6 & 0 & Type 1 achalasia & Pneumatic dilation \\
\hline Patient 12 & 70 & M & 41.8 & 4 & Type 2 achalasia & Pneumatic dilation \\
\hline Patient 13 & 51 & $\mathrm{~F}$ & 51.2 & 1 & Type 2 achalasia & Balloon dilation, pneumatic dilation \\
\hline Patient 14 & 34 & $\mathrm{~F}$ & 25.9 & 0 & EGJ & Balloon dilation, botulinum injection \\
\hline Patient 15 & 29 & $\mathrm{~F}$ & 21.8 & 0 & Type 1 achalasia & N/A \\
\hline
\end{tabular}

BMI, body mass index; CCI, Charlson Comorbidity Index; EGJ, esophagogastric junction outflow obstruction; N/A, not available; NOS, achalasia type not otherwise specified or unable to be determined. 


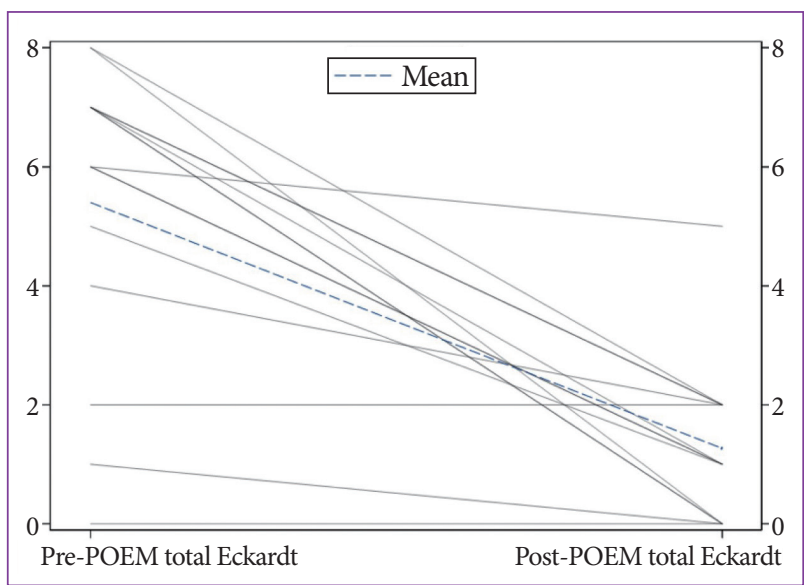

Fig. 4. Mean and individual changes in total Eckardt scores pre- and postperoral endoscopic myotomy (POEM).

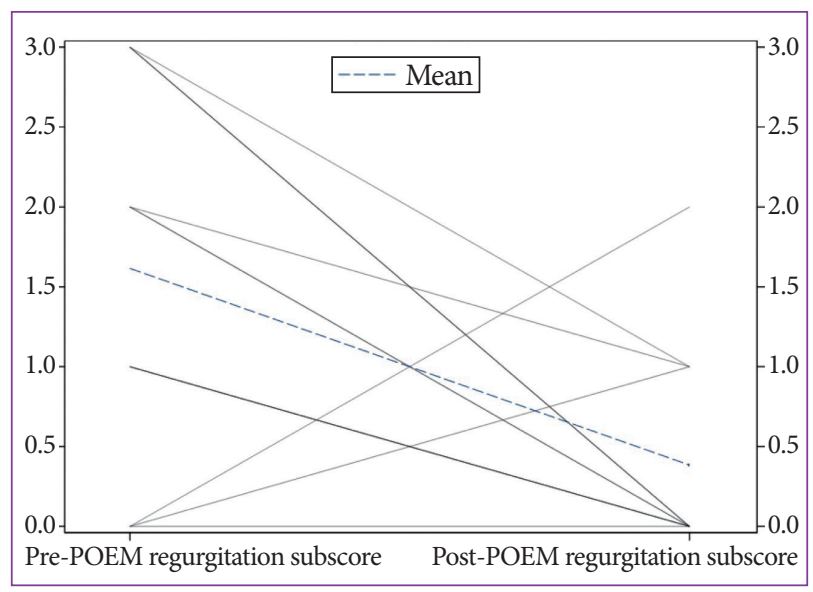

Fig. 6. Mean and individual changes in Eckardt scores for regurgitation subscore. POEM, peroral endoscopic myotomy.

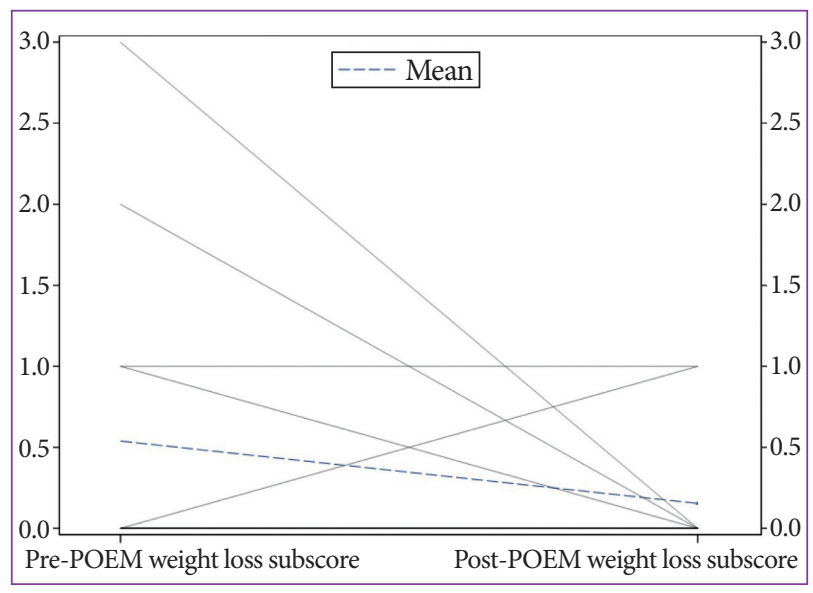

Fig. 8. Mean and individual changes in Eckardt scores for weight loss subscore. POEM, peroral endoscopic myotomy.

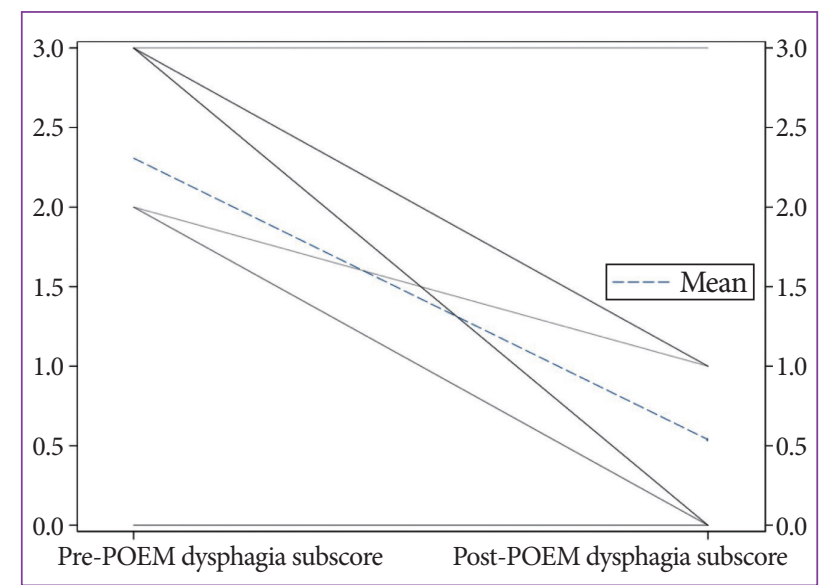

Fig. 5. Mean and individual changes in Eckardt scores for dysphagia subscore. POEM, peroral endoscopic myotomy.

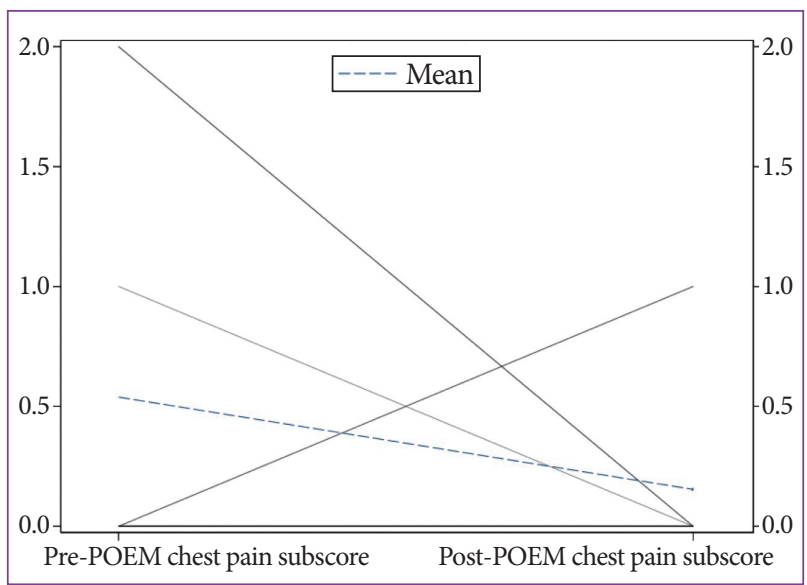

Fig. 7. Mean and individual changes in Eckardt scores for chest pain subscore. POEM, peroral endoscopic myotomy.

event, and two (13.3\%) experienced a moderate adverse event. None of the patients experienced a severe adverse event (Table 2). The most common treatment-related adverse events were post-procedure pain requiring medical team evaluation in the immediate $24-48$ hours after the procedure (4/15 patients, $26.7 \%$ ) and symptomatic reflux requiring $>8$ weeks of PPI therapy and/or additional over-the-counter medications (4/15 patients, 26.7\%). One patient (6.7\%) experienced a capnoperitoneum that required placement of an angiocatheter for decompression but did not experience any further complication nor hemodynamic instability. Two patients (13.3\%) experienced post-procedure pulmonary instability. Of them, one required intubation for laryngeal edema, while the second experienced hypercarbia due to oversedation, but did not require intubation. None of the patients required blood transfusion, chest tube placement, or enteral nutrition. 
Table 2. Treatment and Non-Treatment Related Adverse Events

\begin{tabular}{|c|c|c|c|}
\hline Adverse event severity & Severity definition & $\begin{array}{l}\text { Electrocautery } \\
\text { scissors }(n=15)\end{array}$ & Further descriptors \\
\hline None, $n(\%)$ & & $7(46.7)$ & \\
\hline Mild, $n(\%)$ & $\begin{array}{l}\text { Required post-procedure } \\
\text { medical consultation, } \\
\text { unplanned prolongation of } \\
\text { hospital stay for } \leq 3 \text { nights }\end{array}$ & $6(40)$ & $\begin{array}{l}\text { Inadequate pain control (4), post-procedure reflux (4), } \\
\text { mucosal injury (1), pulmonary instability (1) } \\
\text { capnoperitoneum requiring decompression (1), } \\
\text { post-op infection (1) }\end{array}$ \\
\hline Moderate, $n(\%)$ & $\begin{array}{l}\text { Required additional monitoring: } \\
\text { LOS } 4-10 \text { nights, } \\
\text { and/or ICU admission of } 1 \text { night }\end{array}$ & $2(13.3)$ & $\begin{array}{l}\text { Pulmonary instability }(1)^{\text {b) }} \text {, post-op infection (1), } \\
\text { pleural effusion (1) }\end{array}$ \\
\hline Severe, $n(\%)$ & $\begin{array}{l}\text { Potentially life-threatening; } \\
\text { requiring LOS > } 10 \text { nights, } \\
\text { ICU monitoring > 1 night, } \\
\text { and/or surgical intervention } \\
\text { for adverse event }\end{array}$ & $0(0)$ & Pneumothorax $(0)$, perforation $(0)$, enteral nutrition $(0)$ \\
\hline
\end{tabular}

ICU, intensive care unit; LOS, length of hospital stay; post-op, postoperative.

${ }^{a}$ Pulmonary instability, non-treatment related: hypercarbia due to oversedation not requiring intubation or ICU stay.

${ }^{b)}$ Pulmonary instability, non-treatment related: required intubation due to laryngeal edema and required ICU stay for 1 night.

\section{DISCUSSION}

In 2010, Inoue et al. first reported POEM as a safe and effective treatment option for the treatment of achalasia. ${ }^{3}$ Since that time, multiple other retrospective and prospective trials have reported on the efficacy and safety of POEM. ${ }^{1,6-24}$ Although the steps of the procedure are generally the same worldwide, there is some variability with regard to the equipment used to perform POEM. ${ }^{1,2}$ In the previous years, the two knives that were used by all POEM operators were the triangle tip (TT) knife (Olympus) and the T-type hybrid knife (Erbe). ${ }^{25}$ The conventional knife had been the TT knife. However, some endoscopists prefer the hybrid knife as its usage is associated with shorter operative time, lower bleeding rate, and lower frequency of usage of coagulation forceps. ${ }^{10,25}$ Tang et al. conducted a case-control analysis in 31 achalasia patients who underwent POEM using the hybrid knife and matched them by age, gender, symptom duration, American Society of Anesthesiologists (ASA) Class, Eckardt score, Chicago Classification of achalasia, and LES pressure to 36 patients who underwent POEM using the TT knife. This group confirmed that the use of the hybrid knife decreased the procedure time, decreased the mean frequency of device exchanges, and the mean frequency of coagulation forceps use. ${ }^{1}$ Additionally, they demonstrated no significant difference in the intraoperative or postoperative complications between the two groups. ${ }^{1}$
In recent years, a novel scissor-type knife has been approved for use in the United States. The EES device was initially developed by Honma et al. in 2010 for endoscopic submucosal dissection (ESD) ${ }^{26,27}$ These knives have a curved, insulated tip with an internal cutting mechanism that allows the endoscopist to keep the proper dissecting layer and prevent unexpected muscular layer injuries during submucosal dissection. ${ }^{26}$ Furthermore, Yamashina et al. demonstrated in a single-center phase II trial that the use of the scissor-type knife significantly improved the trainees' self-completion rates for colorectal ESD, without an increase in procedure time or adverse events. ${ }^{28}$ Thus, given the stability and ease of use of the device, it allows for safe handling by both expert level clinicians and fellowship trainees. ${ }^{28,29}$ Although previous studies have investigated the role of EES device in ESD, no original studies have evaluated the efficacy and safety of the device in POEM. In addition to the improved accuracy and precision for dissection, as well as the improved safety in training fellows, the EES device also provides hemostasis without the need for device exchanges. In our study, we investigated the technical and clinical efficacy, as well as the safety of EES device in POEM at an academic institution with a fellowship training program.

We demonstrated a 100\% technical success rate of myotomy (15/15 patients) and a clinical success rate of $93 \%$ (14/15 patients), which is comparable to those of previous studies. ${ }^{1,30}$ The patient in whom we did not achieve clinical success had a 
previous history of lung adenocarcinoma. She previously underwent surgical resection, chemotherapy, and radiation therapy, and had higher risk of disease recurrence. Although the patient's manometry results were possibly consistent with type 1 achalasia, the report also indicated that there was absence of contractility, which was evidenced by the setting of malignancy and/or a paraneoplastic process (i.e., secondary achalasia). Secondary achalasia in the setting of lung cancer has been previously described. ${ }^{31}$ In contrast to primary achalasia in which various treatment options, including POEM, are available, the management of secondary achalasia generally involves treatment of the underlying cause. Although some theories suggest that POEM is less likely to succeed in patients with secondary achalasia, this needs to be further explored.

There was a statistically significant decline in the pre- and post-POEM Eckardt scores $5.4 \pm 2.5$ and $1.3 \pm 1.3$, respectively, mean improvement: $4.1 \pm 2.7(p \leq 0.0001)$. On sub-group analysis, there was a statistically significant improvement in dysphagia $(p=0.0001)$ and regurgitation $(p=0.0136)$. Although we did not observe a statistically significant improvement in chest pain or weight loss, these symptoms did not predominate in the pre-POEM assessment in our patient cohort; thus, there was less room for improvement in the post-POEM scores.

Notably, gastroenterology fellows participated in the myotomy in each procedure. As mentioned previously, given the stability and ease of use of the device, it allows for safe handling by both expert level clinicians and fellowship trainees, ${ }^{28,29}$ and similar outcomes were observed in our POEM cohort. While using the EES device, fellows can grasp the inner circular muscle prior to the incision. Thus, the fellow and attending physician can verbalize agreement in the location of the device prior to the next cut, which improves accuracy and safety of each step as the myotomy progresses distally toward the stomach. In addition, the EES device can be used for empiric vessel sealing and hemostasis, which precludes the need to exchange devices for similar treatment. These are not possible with the needle-knife devices, the unprotected tip of which can often result in inadvertent mucosal injury, arterial bleeding, or full-thickness myotomy especially when performed by trainees. Thus, the use of EES device likely increases the safety of the device over more conventional techniques.

Additionally, to further increase safety and efficacy with trainee involvement, we used two attachment caps and two endoscopic knives to perform each POEM procedure. The combination of the tapered tip cap and needle-type knife facilitates safe entry to the submucosal space and effective submucosal tunneling. By contrast, the EES device did not appear to be useful for the submucosal tunneling, due to the narrow working space of the tunnel. The transition to a combination of the regular cap and EES device allowed us to safely and selectively perform the endoscopic myotomy as described. However, the use of more endoscopic tools and devices can be a disadvantage to the use of the EES device for myotomy. Hence, future studies should investigate the cost effectiveness of the use of these multiple devices; however, given the 100\% technical success rate and lack of adverse events, our technique may be useful in the ongoing education of trainees despite the potential increase in cost. A second potential disadvantage for use of EES for myotomy is that the use of multiple devices may also increase procedure time. Although our mean procedure time of $84 \pm 29$ minutes is comparable to that of previous studies, ${ }^{32}$ it appears slightly longer than other published data. $\mathrm{Li}$ et al. reported a mean operative time of 66.7 minutes in 373 POEM procedures, ${ }^{33}$ while Li et al. reported a median operative time of 45 minutes. ${ }^{34}$ However, the Endoflip device was used in three of the fifteen procedures, and we are unfortunately unable to delineate the time spent solely on the POEM procedure; thus, our POEM procedure times for these cases are falsely elevated as we cannot specify the exact time spent on the POEM itself. There was also a learning curve associated with our technique, as these were the first fifteen procedures performed by our endoscopists. Thus, further comparative studies on procedure time are necessary to elucidate whether the use of multiple devices causes a statistically significant prolongation of the POEM procedure.

While eight of the fifteen patients (53\%) included in this analysis experienced a treatment-related adverse event, most were either mild (40\%), requiring no additional hospital monitoring or procedures, or moderate (13.3\%). None of the patients experienced severe adverse events, which led to life-threatening scenarios or led to prolonged hospitalization or re-admission. One potential advantage of the use of EES, as specified above, is that it may reduce muscle damage due to more precise control of the device during myotomy. We only had one patient with capnoperitoneum requiring decompression, and none developed clinically significant pneumomediastinum, pneumothorax, or perforation, or required enteral nutrition. Four patients (26.7\%) experienced inadequate pain control post-procedure. One prior study evaluating $234 \mathrm{pa}-$ tients post-POEM cited that $8.4 \%-12.6 \%$ of patients had severe postoperative pain (defined as requiring narcotic administration) following POEM. ${ }^{8}$ Thus, our results might indicate a higher than expected rate of post-procedure pain; however, our results are limited by the small sample size. Without a formalized definition of post-procedure pain, further follow-up data are needed to clarify the significance of this result. Four patients (26.7\%) also experienced symptomatic reflux that required prolonged ( $>$ standard 8 weeks) PPI therapy and/or additional over-the-counter antacid medications. Our results are comparable to those of previous data, including a system- 
atic review and meta-analysis in which Repici and colleagues demonstrated a pooled rate of reflux symptoms of 19\% (95\% confidence interval, 15.7\%-22.8\%) after POEM. ${ }^{35}$ Although two patients experienced pulmonary instability post-POEM, both were unrelated to myotomy. One had laryngeal edema due to intubation, while the other had sedation-related hypercarbia, which ultimately resolved without intervention.

Shimizu et al. recently published the results of four patients who underwent POEM with the use of EES; all four procedures were successful, and Shimizu group also deemed it to be a feasible and safe device to use for this procedure. ${ }^{36}$ However, to our knowledge, this is the first original study to investigate the clinical efficacy and safety of the use of EES for myotomy in POEM. However, our study has several limitations. As with all retrospective and non-randomized studies, it is subject to bias. Additionally, our sample size is relatively small with short-term follow-up.

In conclusion, this study demonstrated the technical and clinical efficacy, and an excellent safety profile of EES when used to perform a selective myotomy in POEM in the treatment of achalasia. Additionally, this appears to be an effective tool for safely training fellows how to perform the myotomy technique.

\section{Conflicts of Interest}

Hiroyuki Aihara is a consultant for Olympus, Boston Scientific, and Fujifilm Medical Systems. Christopher C. Thompson has the following disclosures: Apollo Endosurgery - consultant/research support (consulting fees/institutional research grants), Aspire Bariatrics - research support (institutional research grant), BlueFlame Healthcare Venture Fund - general partner, Boston Scientific - consultant (consulting fees), Covidien/Medtronic - consultant (consulting Fees), EnVision Endoscopy (board member), Fractyl - consultant/advisory board member (consulting fees), GI Dynamics - consultant (consulting fees)/research support (institutional research grant), GI Windows - ownership interest, Olympus/Spiration - consultant (consulting fees)/research support (equipment loans), Spatz - research support (institutional research grant), USGI Medical - consultant (consulting fees)/ advisory board member (consulting fees)/research support (research grant). The other authors have no financial conflicts of interest.

\section{Acknowledgments}

This research was partially funded by the NIH T32 training grant DK007533035.

\author{
Author Contributions \\ Conceptualization: Kelly E. Hathorn, Walter W. Chan, Hiroyuki Aihara, \\ Christopher C. Thompson \\ Data curation: KEH \\ Formal analysis: KEH, WWC \\ Funding acquisition: CCT \\ Investigation: $\mathrm{KEH}, \mathrm{HA}, \mathrm{CCT}$ \\ Methodology: HA, CCT \\ Project administration: HA, CCT \\ Resources: CCT \\ Software: WWC, CCT \\ Supervision: HA, CCT
}

Validation: WWC, CCT

Visualization: WWC, HA, CCT

Writing-original draft: $\mathrm{KEH}$

Writing-review\&editing: WWC, HA, CCT

ORCID

Kelly E. Hathorn: https://orcid.org/0000-0002-5677-7383

Walter W. Chan: https://orcid.org/0000-0002-1709-8230

Hiroyuki Aihara: https://orcid.org/0000-0003-2518-6035

Supplementary Material

Video 1. Endoscopic myotomy with use of the electrocautery enhanced scissors (https://doi.org/10.5946/ce.2019.214.v001).

\section{REFERENCES}

1. Tang X, Gong W, Deng Z, et al. Comparison of conventional versus hybrid knife peroral endoscopic myotomy methods for esophageal achalasia: a case-control study. Scand J Gastroenterol 2016;51:494-500.

2. Stavropoulos SN, Modayil RJ, Friedel D, Savides T. The international per oral endoscopic myotomy survey (IPOEMS): a snapshot of the global POEM experience. Surg Endosc 2013;27:3322-3338.

3. Inoue $\mathrm{H}$, Minami $\mathrm{H}$, Kobayashi $\mathrm{Y}$, et al. Peroral endoscopic myotomy (POEM) for esophageal achalasia. Endoscopy 2010;42:265-271.

4. Olympus. SB knives [Internet]. Center Valley (PA): Olympus America; c2020 [cited 2020 Jan 28]. Available from: https://medical.olympusamerica.com/products/sb-knives.

5. Cotton PB, Eisen GM, Aabakken L, et al. A lexicon for endoscopic adverse events: report of an ASGE workshop. Gastrointest Endosc 2010;71:446-454.

6. Schlottmann F, Luckett DJ, Fine J, Shaheen NJ, Patti MG. Laparoscopic Heller myotomy versus peroral endoscopic myotomy (POEM) for achalasia: a systematic review and meta-analysis. Ann Surg 2018;267:451460.

7. Von Renteln D, Fuchs KH, Fockens P, et al. Peroral endoscopic myotomy for the treatment of achalasia: an international prospective multicenter study. Gastroenterology 2013;145:309-311.e1-e3.

8. Li QL, Chen WF, Zhou PH, et al. Peroral endoscopic myotomy for the treatment of achalasia: a clinical comparative study of endoscopic full-thickness and circular muscle myotomy. J Am Coll Surg 2013;217:442-451.

9. Minami H, Isomoto H, Yamaguchi N, et al. Peroral endoscopic myotomy for esophageal achalasia: clinical impact of 28 cases. Dig Endosc 2014;26:43-51.

10. Cai MY, Zhou PH, Yao LQ, et al. Peroral endoscopic myotomy for idiopathic achalasia: randomized comparison of water-jet assisted versus conventional dissection technique. Surg Endosc 2014;28:1158-1165.

11. Ling TS, Guo HM, Yang T, Peng CY, Zou XP, Shi RH. Effectiveness of peroral endoscopic myotomy in the treatment of achalasia: a pilot trial in Chinese Han population with a minimum of one-year follow-up. J Dig Dis 2014;15:352-358.

12. Patel KS, Calixte R, Modayil RJ, Friedel D, Brathwaite CE, Stavropoulos SN. The light at the end of the tunnel: a single-operator learning curve analysis for per oral endoscopic myotomy. Gastrointest Endosc 2015;81:1181-1187.

13. Chen X, Li QP, Ji GZ, et al. Two-year follow-up for 45 patients with achalasia who underwent peroral endoscopic myotomy. Eur J Cardiothorac Surg 2015;47:890-896.

14. Kumagai K, Tsai JA, Thorell A, Lundell L, Håkanson B. Per-oral endoscopic myotomy for achalasia. Are results comparable to laparoscopic Heller myotomy? Scand J Gastroenterol 2015;50:505-512. 
15. Liu XJ, Tan YY, Yang RQ, et al. The outcomes and quality of life of patients with achalasia after peroral endoscopic myotomy in the shortterm. Ann Thorac Cardiovasc Surg 2015;21:507-512.

16. Sharata AM, Dunst CM, Pescarus R, et al. Peroral endoscopic myotomy (POEM) for esophageal primary motility disorders: analysis of 100 consecutive patients. J Gastrointest Surg 2015;19:161-170; discussion 170.

17. Inoue $\mathrm{H}$, Sato $\mathrm{H}$, Ikeda $\mathrm{H}$, et al. Per-oral endoscopic myotomy: a series of 500 patients. J Am Coll Surg 2015;221:256-264.

18. Hu Y, Li M, Lu B, Meng L, Fan Y, Bao H. Esophageal motility after peroral endoscopic myotomy for achalasia. J Gastroenterol 2016;51:458-464.

19. Werner YB, Costamagna G, Swanström LL, et al. Clinical response to peroral endoscopic myotomy in patients with idiopathic achalasia at a minimum follow-up of 2 years. Gut 2016;65:899-906.

20. Schneider AM, Louie BE, Warren HF, Farivar AS, Schembre DB, Aye RW. A matched comparison of per oral endoscopic myotomy to laparoscopic Heller myotomy in the treatment of achalasia. J Gastrointest Surg 2016;20:1789-1796.

21. Lv L, Liu J, Tan Y, Liu D. Peroral endoscopic full-thickness myotomy for the treatment of sigmoid-type achalasia: outcomes with a minimum follow-up of 12 months. Eur J Gastroenterol Hepatol 2016;28:30-36.

22. Worrell SG, Alicuben ET, Boys J, DeMeester SR. Peroral endoscopic myotomy for achalasia in a thoracic surgical practice. Ann Thorac Surg 2016;101:218-224; discussion 224-225.

23. Hungness ES, Sternbach JM, Teitelbaum EN, Kahrilas PJ, Pandolfino JE, Soper NJ. Per-oral endoscopic myotomy (POEM) after the learning curve: durable long-term results with a low complication rate. Ann Surg 2016;264:508-517.

24. Familiari P, Gigante G, Marchese M, et al. Peroral endoscopic myotomy for esophageal achalasia: outcomes of the first 100 patients with shortterm follow-up. Ann Surg 2016;263:82-87.

25. Stavropoulos SN, Iqbal S, Modayil R, Dejesus D. Per oral endoscopic myotomy, equipment and technique: a step-by-step explanation. Video Journal and Encyclopedia of GI Endoscopy 2013;1:96-100.
26. Ko BM. History and development of accessories for endoscopic submucosal dissection. Clin Endosc 2017;50:219-223.

27. Honma K, Kobayashi M, Watanabe H, et al. Endoscopic submucosal dissection for colorectal neoplasia. Dig Endosc 2010;22:307-311.

28. Yamashina T, Takeuchi Y, Nagai $K$, et al. Scissor-type knife significantly improves self-completion rate of colorectal endoscopic submucosal dissection: single-center prospective randomized trial. Dig Endosc 2017;29:322-329.

29. Ge PS, Thompson CC, Aihara H. Endoscopic submucosal dissection of a large cecal polyp using a scissor-type knife: implications for training in ESD. VideoGIE 2018;3:313-315.

30. Nabi Z, Ramchandani M, Chavan R, et al. Per-oral endoscopic myotomy for achalasia cardia: outcomes in over 400 consecutive patients. Endosc Int Open 2017;5:E331-E339.

31. Hirano T, Miyauchi E, Inoue A, et al. Two cases of pseudo-achalasia with lung cancer: case report and short literature review. Respir Investig 2016;54:494-499.

32. Barbieri LA, Hassan C, Rosati R, Romario UF, Correale L, Repici A. Systematic review and meta-analysis: efficacy and safety of POEM for achalasia. United European Gastroenterol J 2015;3:325-334.

33. Li H, Peng W, Huang S, et al. The 2 years' long-term efficacy and safety of peroral endoscopic myotomy for the treatment of achalasia: a systematic review. J Cardiothorac Surg 2019;14:1.

34. Li QL, Wu QN, Zhang XC, et al. Outcomes of per-oral endoscopic myotomy for treatment of esophageal achalasia with a median follow-up of 49 months. Gastrointest Endosc 2018;87:1405-1412.e3.

35. Repici A, Fuccio L, Maselli R, et al. GERD after per-oral endoscopic myotomy as compared with Heller's myotomy with fundoplication: a systematic review with meta-analysis. Gastrointest Endosc 2018;87:934943.e18.

36. Shimizu T, Fortinsky KJ, Chang KJ. Early experience with use of an endoscopic "hot" scissor-type knife for myotomy during per-oral endoscopic myotomy procedure. VideoGIE 2019;4:182-184. 